\title{
EL DERECHO A LA TUTELA JUDICIAL EFECTIVA Y EL DERECHO A LA EJECUCIÓN EN LA JURISPRUDENCIA CONSTITUCIONAL*
}

\section{The right to effective judicial protection and the right to execution in constitutional jurisprudence}

\author{
Ignacio José Cubillo López \\ Universidad de Córdoba (España) \\ dc1cubli@uco.es
}

http://dx.doi.org/10.18543/ed-66(2)-2018pp347-372

Recibido: 30.10 .2018

Aceptado: 21.11.2018

\section{Resumen}

En este trabajo se estudia la delimitación que realiza el Tribunal Constitucional en su jurisprudencia del derecho a la tutela judicial efectiva, en su vertiente de derecho a la ejecución. Se examina así el alcance constitucional del derecho de la ejecución de la sentencia en sus propios términos, y el de su precedente lógico, el derecho a la invariabilidad de las resoluciones judiciales firmes.

\section{Palabras clave}

Tutela judicial efectiva; Derecho a la ejecución; Invariabilidad de las resoluciones; Cosa juzgada; Ejecución sustitutoria.

* Cómo citar / Citation 'Chicago-Deusto' (Autor-fecha / Author-date / Lista de referencias / Reference list entries): Cubillo López, Ignacio José. 2018. «El derecho a la tutela judicial efectiva y el derecho a la ejecución en la jurisprudencia constitucional». Estudios de Deusto 66, n. ${ }^{\circ}$ 2: 347-372. http://dx.doi.org/10.18543/ed-66(2)-2018pp347-372.

Proyecto de Investigación «Administración pública y derechos fundamentales: nuevas perspectivas», DER2015-67695-C2-2-P (MINECO/FEDER). 


\section{Abstract}

This paper studies the delimitation that the Constitutional Court makes in its jurisprudence of the right to effective judicial protection, in its aspect of right to execution. This examines the constitutional scope of the right to enforce the judgment on its own terms, and that of its logical precedent, the right to the invariability of final judicial decisions.

\section{Keywords}

Effective judicial protection; Right to execution; Invariability of resolutions; Juged thing; Substitute execution. 


\begin{abstract}
Sumario: I. Delimitación JURISPRUDENCIAL DEL CONTENIDO DEL DERECHO A LA TUTELA JUDICIAL EFECTIVA. II. EL DERECHO A LA EJECUCIÓN COMO PARTE INTEGRANTE DEL DERECHO A LA TUTELA JUDICIAL EFECTIVA. III. RELACIÓN ENTRE EL DERECHO A LA EJECUCIÓN Y EL DERECHO A LA COSA JUZGADA. IV. EL DERECHO A LA EJECUCIÓN DE LA SENTENCIA EN SUS PROPIOS TÉRMINOS.
\end{abstract}

\title{
I. DELIMITACIÓN JURISPRUDENCIAL DEL CONTENIDO DEL DERECHO A LA TUTELA JUDICIAL EFECTIVA
}

El presente trabajo se ha elaborado dentro del Proyecto de Investigación financiado por el Ministerio de Economía y Competitividad y titulado «Administración pública y derechos fundamentales: nuevas perspectivas» (ref. DER2015-67695-C2-2-P), cuyo investigador principal es el Prof. Dr. Rodríguez Portugués, de la Universidad de Córdoba; y a su vez se enmarca en un número monográfico de la Revista Estudios de Deusto, dedicado al tema «Los derechos fundamentales entre la Justicia y la Administración Pública». El objeto tanto del citado proyecto de investigación como del presente número ha consistido principalmente en estudiar la determinación del contenido y de los límites de los derechos fundamentales que es efectuada por órganos públicos - por poderes del Estado- distintos del Poder Legislativo, esto es, por la Administración Pública y por la Jurisdicción. Pues es sabido que el artículo 53.1 de la Constitución señala que los derechos y libertades fundamentales -regulados en el Capítulo segundo del Título I-, de una parte, vinculan a todos los poderes públicos, y de otra, sólo por ley se regulará su ejercicio, teniendo estas leyes que respetar en todo caso el contenido esencial de los mismos; sin embargo, ocurre que buena parte de lo que son y de hasta dónde llegan los derechos fundamentales no se delinea a través del articulado de leyes que los desarrollen, sino que se realiza por otras vías, como son la actividad administrativa y la actividad jurisdiccional.

Un ejemplo eminente de derecho fundamental delimitado por el quehacer de los tribunales, y en particular por la labor jurisprudencial que corresponde al TC en virtud del artículo 5 de la LOPJ, es el llamado derecho a la tutela judicial efectiva, recogido en el artículo 24.1 de la CE con el siguiente tenor literal: «Todas las personas tienen derecho a obtener la tutela efectiva de los jueces y tribunales en el ejercicio de sus derechos e intereses legitimos, sin que, en ningún caso, pueda producirse indefensión». Es bien sabido que este derecho no es un único derecho fundamental, sino que se compone de una pluralidad de derechos fundamentales a disposición de los «justiciables», o 
ciudadanos en cuanto que se relacionan con la Administración de Justicia ${ }^{1}$. Ha sido la jurisprudencia del TC la que ha ido delimitando a lo largo de los años cuáles son los derechos fundamentales que se integran en el derecho a la tutela judicial efectiva y hasta dónde alcanza el contenido de cada uno de ellos. Por su propia naturaleza, esta delimitación ha sido progresiva, se ha basado en casos concretos y siempre resulta un tanto incompleta. Pero existe un cuerpo sólido de doctrina, emanada de multitud de sentencias, que posteriormente ha influido e influye tanto en el Legislador que ha de promulgar leyes que afecten a los derechos fundamentales implicados, como en los tribunales de la jurisdicción ordinaria, en su tarea de aplicar las normas legales al resolver controversias.

De manera muy sintética, exponemos a continuación el contenido esencial de los principales derechos fundamentales comprendidos en el derecho a la tutela judicial efectiva, según la jurisprudencia constitucional ${ }^{2}$.

$1^{\circ}$ ) En primer lugar, todos los ciudadanos tienen un derecho de acceso a la jurisdicción, es decir, han de tener la posibilidad de acudir a los órganos jurisdiccionales y de formular ante ellos peticiones de tutela, y que estas solicitudes tengan una respuesta judicial que esté fundada en Derecho, aunque sea de inadmisión. Ni el Legislador debe establecer requisitos o condiciones para el acceso a la jurisdicción que sean irracionales o excesivos o desproporcionados respecto del fin que cumplan (que, por supuesto, ha de ser legítimo); ni los tribunales han de interpretar estos requisitos legales de forma restrictiva para el acceso a la jurisdicción, sino que, al contrario, habrán de ajustarse al llamado «principio pro actione», que exige analizar las causas legales de inadmisión de la demanda de una forma que sea razonable y favorable al ejercicio de la acción, permitiendo la subsanación de los defectos existentes, siempre que sea posible. Ahora bien, esta regla no debe llevarse al

${ }^{1}$ Para De la Oliva Santos (con Díez-Picazo Giménez y Vegas Torres, J., en Curso de Derecho Procesal Civil I. Parte General, Editorial Universitaria Ramón Areces, Madrid, $3^{\text {a }}$ ed., 2016, p. 137): «Se entiende por justiciable todo sujeto jurídico en cuanto puede entrar en relación con la Jurisdicción o Administración de Justicia o en cuanto, de modo actual, es protagonista principal del proceso». Y este autor se refiere al contenido complejo del derecho a la tutela judicial efectiva señalando que «el tan repetido derecho fundamental sirve de rótulo general para un conjunto de derechos subjetivos, elevados ex Constitutione a un rango superior, el de derechos fundamentales», enumerando y glosando a continuación los derechos fundamentales que se entienden ahí incluidos (ob. cit., pp. 157 a 161).

2 Para un desarrollo de la jurisprudencia sobre estos derechos, con carácter general, destacan las obras: Garberí Llobrregat, J., El derecho a la tutela judicial efectiva en la jurisprudencia del Tribunal Constitucional, Bosch, Barcelona, 2008; Ruiz-Rico Ruiz y Carazo Liébana, M. J., El derecho a la tutela judicial efectiva. Análisis jurisprudencial, Tirant lo Blanch, Valencia, 2013; y Salah Palacios, E., La tutela judicial efectiva en la jurisprudencia del Tribunal Constitucional 1981-2014, Cultiva Libros, Madrid, 2015. 
extremo, sino que ha de entenderse en su justa medida, como trata de precisar, entre otras muchas, la STC 218/2009, de 21 de diciembre (FJ 2):

«Dada la trascendencia que para la tutela judicial tienen estas decisiones de denegación de acceso a la jurisdicción, su control constitucional ha de realizarse de forma especialmente intensa: más allá de la verificación de que no se trata de resoluciones arbitrarias, manifiestamente irrazonables o fruto de un error patente, tal control procede a través de los criterios que proporciona el principio pro actione, entendido no «como la forzosa selección de la interpretación más favorable a la admisión de entre todas las posibles de las normas que la regulan», sino como «la interdicción de aquellas decisiones de inadmisión que por su rigorismo, por su formalismo excesivo o por cualquier otra razón revelen una clara desproporción entre los fines que aquellas causas preservan y los intereses que sacrifican» (STC 88/1997, de 5 de mayo, FJ 2)». Otras sentencias que van en la misma línea, por citar sólo algunas más, son las SSTC 185/2006, de 19 de junio (FJ 6); 1/2007, de 15 de enero (FJ 2); y 26/2008, de 11 de febrero (FJ 5)³.

$2^{\circ}$ ) En segundo lugar, el derecho a la tutela judicial efectiva no se queda en el derecho de acudir a los tribunales para plantear peticiones de tutela o formular pretensiones que obtengan una respuesta fundada en Derecho, sino que también comprende el derecho a que los órganos jurisdiccionales se pronuncien sobre la pretensión formulada y dicten así una resolución sobre el fondo del asunto, con independencia de que ésta sea estimatoria o desestimatoria de la pretensión. Por tanto, además del derecho fundamental de acceder a la jurisdicción, existe otro derecho fundamental a que los tribunales inicien un proceso, éste se desarrolle - permitiendo al justiciable participar en él-y llegue hasta el final con una resolución que decida la cuestión sustantiva planteada ${ }^{4}$. Este derecho fundamental, denominado por la doctrina «derecho al proceso ${ }^{5}$,

${ }^{3}$ Garberí Llobregat realiza un estudio detallado del contenido y de las consecuencias del derecho de acceso, según la jurisprudencia constitucional: ver ob. cit., pp. 27 a 66. Sobre otras manifestaciones más actuales del derecho de acceso, ver sendos trabajos publicados en este mismo número monográfico de Peiteado Mariscal, «Consideraciones sobre la relación entre el derecho a la tutela judicial efectiva y la mediación obligatoria», y Catalán Chamorro, «El Derecho Fundamental de Acceso a la Justicia de los Consumidores».

${ }^{4}$ Como afirma Garberí Llobregat (ob. cit., p. 78): «la única clase de resoluciones judiciales capaces de contener un pronunciamiento sobre los términos concretos de la controversia sometida a los tribunales, una decisión que se manifieste acerca de a cuál de los litigantes, y en qué medida, es al que asiste el Derecho objetivo, son las denominadas resoluciones judiciales de fondo (generalmente, las que revisten forma de sentencia)».

5 Así, De la Oliva Santos: «Con la denominación «derecho al proceso» se designa el derecho subjetivo público de quien solicita una concreta tutela de los tribunales a obtener una sentencia que se pronuncie sobre tal solicitud... derecho a una sentencia sobre el fondo, que entraña, no una actividad jurisdiccional cualquiera, sino precisamente toda la 
por supuesto no es un derecho incondicional, se encuentra supeditado al cumplimiento de los requisitos procesales legalmente establecidos; por lo que se satisface igualmente cuando el tribunal dicta un resolución de carácter procesal, que no entra a resolver sobre el fondo en caso de que se incumpla alguno de los requisitos exigidos, siempre que esto se aprecie de forma razonable y coherente con el antes mencionado «principio pro actione». Así, entre otras muchas, la STC 256/2007, de 10 de diciembre (FJ 2):

«Así centrado el objeto del debate, hemos de recordar que constituye una garantía esencial del justiciable que el derecho a la tutela judicial efectiva comprenda el de obtener una resolución fundada en Derecho sobre el fondo de las cuestiones planteadas, sea o no favorable a las pretensiones formuladas, si concurren todos los requisitos para ello. De ahí que este Tribunal haya sostenido que son conformes con el derecho fundamental que consagra el art. 24.1 CE las resoluciones judiciales de inadmisión, o de desestimación que se fundamenten en óbices procesales, cuando concurra alguna causa de inadmisibilidad y así lo acuerde el Juez o Tribunal en aplicación razonada de la misma (SSTC 71/2002, de 8 de abril, FJ 1; 59/2003, de 24 de marzo, FJ 2; 114/2004, de 12 de julio, FJ 3; 79/2005, de 4 de abril, FJ 2; 221/2005, de 12 de septiembre, FJ 2; 339/2006, de 11 de diciembre, FJ 2)».

$3^{\circ}$ ) El derecho a la tutela judicial efectiva incluye igualmente el derecho a que la sentencia que se dicte sobre el fondo del asunto sea motivada y fundada en Derecho. La motivación supone dar razón de los motivos o fundamentos del fallo, tanto fácticos como jurídicos, en un sentido externo; es decir, exige que la sentencia exprese las razones en que apoya la decisión de la controversia, de forma que los justiciables puedan conocerlas y controlar que no son ilógicas o arbitrarias y, en caso contrario, puedan recurrir. En cambio, el requisito de que la sentencia esté fundada en Derecho alude a algo más interno, y es que la resolución no sólo debe exteriorizar las normas y los argumentos jurídicos en que se basa, sino que ha de contener una aplicación real y racional de lo previsto en el Ordenamiento jurídico; esto último supone que resulta lesivo del derecho a la tutela judicial efectiva que en la sentencia, pese a su aparente fundamentación jurídica, se haya efectuado una interpretación de las normas aplicables que sea manifiestamente arbitraria, o irracional, o fruto de un error patente.

Expresa esta doctrina jurisprudencial, por todas, la STC 134/2008, de 23 de octubre (FJ 2), donde se afirma que: «el derecho a la tutela judicial efectiva que reconoce el art. 24.1 CE, en su dimensión de derecho a obtener una resolución judicial fundada en Derecho, favorable o adversa, es

actividad jurisdiccional necesariamente previa a una sentencia sobre el fondo y esa misma sentencia, es decir, todo un proceso» (ob. cit., p. 144 y ss.). 
garantía frente a la arbitrariedad e irrazonabilidad de los poderes públicos. Ello implica, en primer lugar, que la resolución ha de estar motivada, es decir, contener los elementos y razones de juicio que permitan conocer cuáles han sido los criterios jurídicos que fundamentan la decisión; y en segundo lugar, que la motivación debe contener una fundamentación en Derecho, lo que conlleva la garantía de que la decisión no sea consecuencia de una aplicación arbitraria de la legalidad, no resulte manifiestamente irrazonada o irrazonable o incurra en un error patente ya que, en tal caso, la aplicación de la legalidad sería tan sólo una mera apariencia (SSTC 147/1999, de 4 de agosto, FJ 3; 25/2000, de 31 de enero, FJ 2; 87/2000, de 27 de marzo, FJ 6; 82/2001, de 26 de marzo, FJ 2; 221/2001, de 31 de octubre, FJ 6; 55/2003, de 24 de marzo, FJ 6; 223/2005, de 12 de septiembre, FJ 3; 276/2006, de 25 de septiembre, FJ 2; y 177/2007, de 23 de julio, FJ 5; entre otras muchas). De este modo, no cabe reputar como fundadas en Derecho aquellas decisiones judiciales en las que este Tribunal compruebe que parten de premisas inexistentes o patentemente erróneas, o que siguen un desarrollo argumental que incurre en quiebras lógicas de tal magnitud que las conclusiones alcanzadas no pueden considerarse basadas en ninguna de las razones aducidas en la resolución (por todas, SSTC 214/1999, de 29 de noviembre, FJ 4; 223/2002, de 25 de noviembre, FJ 6; 20/2004, de 23 de febrero, FJ 6; y $117 / 2007$, de 23 de julio, FJ 4)».

Lo anterior no significa que los derechos reconocidos en el artículo 24.1 de la CE garanticen «la justicia de la decisión o la corrección jurídica de la actuación o interpretación llevada a cabo por los órganos judiciales comunes, pues no existe un derecho al acierto, ni tampoco aseguran la satisfacción de la pretensión de ninguna de las partes del proceso», como señala la STC 263/2015, de 14 de diciembre (FJ 3)».

Y continúa poco después: «No basta, pues, con obtener una respuesta motivada, sino que, además, ésta ha de tener contenido jurídico y no resultar arbitraria. Y una resolución judicial puede tacharse de arbitraria cuando, aun constatada la existencia formal de una argumentación, la misma no es expresión de la administración de justicia sino simple apariencia de la misma por ser fruto de un mero voluntarismo judicial o expresar un proceso deductivo irracional o absurdo (SSTC 148/1994, de 12 de mayo, FJ 4; 244/1994, de 15 de septiembre, FJ 2; 54/1997, de 17 de marzo, FJ 3; 160/1997, de 2 de octubre, FJ 7, y 173/2002, de 9 de octubre FJ 6)». En esta sentencia, el TC estimó que hubo violación del artículo 24.1 de la $\mathrm{CE}$ porque la resolución objeto del recurso de amparo contenía formalmente una argumentación jurídica, pero era solo aparente, ya que expresaba un proceso deductivo irracional. Y otro tanto sucedió en otras resoluciones, paralelas a la anterior, como son las SSTC 262/2015, de 14 de diciembre; 240/2015, de 30 de noviembre; 239/2015, de 30 de noviembre; y 222/2015, de 2 de noviembre. 
$\left.4^{\circ}\right)$ La respuesta judicial sobre el fondo y fundada a que tienen derecho los justiciables también ha de ser congruente con sus pretensiones, como parte del derecho a la tutela judicial efectiva. Por tanto, los tribunales deben ofrecer una completa respuesta sobre las pretensiones concretas deducidas en el proceso, y no sobre otras distintas, de manera que el fallo judicial se adecue al objeto procesal perfilado por las partes. Conforme a la jurisprudencia del TC, las modalidades de incongruencia que resultan lesivas del artículo 24.1 de la $\mathrm{CE}$ son tres. En primer término, la incongruencia omisiva o ex silentio, consistente en que la sentencia deja sin resolver alguna de las pretensiones de las partes. Ahora bien, no toda omisión en este sentido tiene relevancia constitucional, es preciso que: $i$ ) la omisión sea explícita e implícita (pues si la respuesta judicial no consta en el fallo pero cabe deducirla de los fundamentos de la sentencia, no se lesionará el derecho a la tutela judicial efectiva); ii) la omisión se refiera a una pretensión, y no a una alegación que sirva de fundamento de la misma, salvo que se trate de una alegación de carácter sustancial (ya que toda pretensión debe encontrar respuesta judicial en la sentencia, pero no ocurre igual con las alegaciones); y iii) dicha omisión, sobre una pretensión o alegación sustancial debatidas en el proceso, debe tener influencia en el fallo (de suerte que, de no haberse producido, el fallo hubiera sido distinto). Contiene una exposición muy completa de las incongruencias omisivas que son constitucionalmente relevantes, por ejemplo, la STC 4/2006, de 16 de enero (FJ 3).

En segundo lugar, también puede tener relevancia constitucional la llamada incongruencia por exceso, que puede ser por extra o por ultra petitum, según que el tribunal resuelva sobre cuestiones distintas, o que van más allá, de la tutela solicitada. En estos casos, para que exista lesión del artículo 24.1 de la $\mathrm{CE}$, el TC requiere que la sentencia se haya apartado de forma sustancial del objeto del proceso, resolviendo sobre algo respecto de lo que las partes no han tenido oportunidad de alegar y de probar, es decir, de ejercitar su derecho de defensa. En este sentido, resulta muy ilustrativa la STC 264/2005, de 24 de octubre.

En este sentido, resulta muy ilustrativa la STC 264/2005, de 24 de octubre (FJ 2) ${ }^{6}$.

${ }^{6}$ El ajuste de lo que resuelva el tribunal con relación al objeto procesal definido por las partes se extiende a sus distintos elementos, incluida la causa de pedir. Y así, el TC recuerda en esta misma sentencia que: «la adecuación debe extenderse tanto al resultado que el litigante pretende obtener, como a los hechos que sustentan la pretensión y al fundamento jurídico que la nutre, sin que las resoluciones judiciales puedan modificar la causa petendi, alterando de oficio la acción ejercitada, pues se habrían dictado sin oportunidad de debate, ni de defensa, sobre las nuevas posiciones en que el órgano judicial sitúa el thema decidendi». Pero a la vez, poco más adelante precisa que: «el principio iura novit curia permite al Juez fundar el fallo en los preceptos legales o normas jurídicas que sean 
El tercer tipo de incongruencia con repercusión en el derecho a la tutela judicial efectiva es el que la jurisprudencia constitucional califica de mixta o por error, que supone la unión de las dos anteriores. Como señala, por ejemplo, la STC 211/2003, de 1 de diciembre (FJ 4): «En ocasiones ambas clases de incongruencia pueden presentarse unidas, concurriendo la llamada «incongruencia por error», denominación adoptada en la STC 28/1987, de 13 de febrero, y seguida por las SSTC 369/1993, de 13 de diciembre y 111/1997, de 3 de junio, que define un supuesto en el que el órgano judicial no resuelve sobre la pretensión formulada en la demanda o sobre el motivo del recurso, sino que erróneamente razona sobre otra pretensión absolutamente ajena al debate procesal planteado, dejando al mismo tiempo aquélla sin respuesta (además de las citadas, SSTC 136/1998, de 29 de junio, FJ 2; y 92/2003, de 19 de mayo, FJ 3)».

$5^{\circ}$ ) Cabe entender que los derechos fundamentales expuestos hasta el momento -el derecho de acceso a la jurisdicción y a obtener una sentencia sobre el fondo, fundada y congruente- forman «los contenidos básicos o estructurales (aquellos sine que non) del derecho a la tutela judicial efectiva», en expresión de algún autor 7 . Pero son más los derechos de carácter fundamental que el TC ha considerado incluidos en el tan repetido derecho del artículo 24.1 de la CE. Entre ellos, destaca el derecho a los recursos previstos legalmente. Así y como es bien sabido, no se reconoce un derecho constitucional a que las leyes procesales prevean recursos -salvo con relación a las sentencias penales de condena, en virtud del artículo 14.5 del PIDCP- sino a que los órganos jurisdiccionales permitan el acceso a los recursos recogidos en las leyes, interpretando conforme al «principio pro actione» los requisitos que se exigen para su admisión a trámite. Aunque esta regla o principio no opera igual en el acceso a los recursos que con el acceso inicial a la jurisdicción, pues para la admisibilidad de un recurso el canon constitucional se satisface con una interpretación que no sea arbitraria o irrazonable o basada en un error patente, sin que se precise efectuar la interpretación más favorable a su admisión.

La STC 37/1995, de 10 de diciembre, marcó un hito a este respecto y en ella se señala (FJ 5): «Es distinto el enjuiciamiento que puedan recibir las normas obstaculizadoras o impeditivas del acceso a la jurisdicción o aquellas

de pertinente aplicación al caso, aunque los litigantes no las hubieren invocado, y que el juzgador sólo está vinculado por la esencia y sustancia de lo pedido y discutido en el pleito, no por la literalidad de las concretas pretensiones ejercitadas, tal y como hayan sido formuladas por los litigantes, de forma que no existirá incongruencia extra petitum cuando el Juez o Tribunal decida o se pronuncie sobre una de ellas que, aun cuando no fuera formal y expresamente ejercitada, estuviera implícita o fuera consecuencia inescindible o necesaria de los pedimentos articulados o de la cuestión principal debatida en el proceso».

7 Garberí Llobregat, ob. cit., p. 135. 
otras que limitan la admisibilidad de un recurso extraordinario contra una Sentencia anterior dictada en un proceso celebrado con todas las garantías (STC 3/1983 y 294/1994)». Así, en este caso, la cuestión se centraba en el modo de interpretar una causa de inadmisión de un recurso de casación, cuando cabían dos interpretaciones posibles, siendo una de ellas más favorecedora de la admisión que la otra; y el TC sentenció (FJ 6): «la cuestión planteada carece de la menor connotación constitucional. Desde esta perspectiva, que es la nuestra, las dos soluciones propugnadas son admisibles, cualquiera que fuere su grado de exactitud relativa respecto de la voluntad objetivada de la Ley o la subjetiva del legislador. No habiéndose cerrado la vía del recurso arbitrariamente o intuitu personae, queda en pie nuestra doctrina al respecto, en cuya virtud corresponde al Tribunal Supremo la última palabra sobre la admisibilidad de los recursos de casación ante él interpuestos, a salvo lo dispuesto en materia de garantías constitucionales (art. 123 C.E.). En definitiva, la balanza constitucional no puede inclinarse en ningún sentido para optar entre dos soluciones igualmente razonables, sin interferir en el núcleo de la potestad de juzgar cuya independencia de criterio predica la Constitución, ya que el amparo no está configurado como una última instancia ni tiene una función casacional, operantes una y otra en el ámbito de la legalidad».

Y junto a los anteriores, el haz de derechos fundamentales comprendidos dentro del derecho a la tutela judicial efectiva resulta más amplio, pues, según el TC, también incluye: $6^{\circ}$ ) el derecho a que durante el proceso se observen sin quiebra los principios jurídico-naturales del mismo, de audiencia e igualdad; $7^{\circ}$ ) el derecho a que los actos de comunicación procesal se practiquen de forma correcta; $8^{\circ}$ ) el derecho a la tutela cautelar durante los procesos declarativos; y muy singularmente, $9^{\circ}$ ) el derecho a la intangibilidad e invariabilidad de las resoluciones firmes, y $10^{\circ}$ ) el derecho a la ejecución forzosa de las sentencias de condena, cuando no exista un cumplimiento voluntario de las mismas. Por su importancia y su intensa relación con la efectividad de la tutela judicial a que tienen derecho los justiciables, y porque pensamos que está menos desarrollado doctrinalmente que otros derechos fundamentales insertos en el artículo 24.1 de la CE, queremos centrar las páginas que siguen en el derecho a la ejecución de sentencias firmes, como auténtico derecho fundamental, pero con la necesaria referencia también a su precedente, el derecho a la intangibilidad de las resoluciones firmes, que muchas sentencias del TC ligan al anterior, configurándolo como el presupuesto lógico y necesario del derecho a la ejecución.

\section{EL DERECHO A LA EJECUCIÓN COMO PARTE INTEGRANTE DEL DERECHO A LA TUTELA JUDICIAL EFECTIVA}

Así, desde muy pronto el Tribunal Constitucional entendió que dentro del derecho a la tutela judicial efectiva se encuentra, como una manifestación 
necesaria, el derecho que los justiciables tienen a que las sentencias que los tribunales ordinarios hayan dictado para la tutela de sus derechos e intereses legítimos se hagan cumplir forzosamente, cuando el destinatario de las mismas -el condenado- no lleve a cabo voluntariamente la prestación a la que se le condene, sea ésta de dar, hacer o no hacer. De otra forma no podría hablarse de una genuina tutela judicial efectiva. Una de las primeras sentencias en este sentido, citada por otras posteriores, fue la STC 32/1982, de 7 de junio (FJ 2):

«Es preciso reconocer que esta situación supone, como afirman los recurrentes, una violación del art. 24.1 de la Constitución. El derecho a la tutela efectiva que dicho artículo consagra no agota su contenido en la exigencia de que el interesado tenga acceso a los Tribunales de Justicia, pueda ante ellos manifestar y defender su pretensión jurídica en igualdad con las otras partes y goce de la libertad de aportar todas aquellas pruebas que procesalmente fueran oportunas y admisibles, ni se limita a garantizar la obtención de una resolución de fondo fundada en derecho, sea o no favorable a la pretensión formulada, si concurren todos los requisitos procesales para ello. Exige también que el fallo judicial se cumpla y que el recurrente sea repuesto en su derecho y compensado, si hubiere lugar a ello, por el daño sufrido: lo contrario sería convertir las decisiones judiciales y el reconocimiento de los derechos que ellas comportan en favor de alguna de las partes, en meras declaraciones de intenciones» ${ }^{8}$.

Este derecho a la ejecución forzosa enlaza así con la potestad jurisdiccional que la Constitución reconoce a los tribunales en su artículo 117, para el ejercicio de la función también calificada de jurisdiccional, y que, como es bien sabido, tiene una vertiente declarativa, consistente en «juzgar» o declarar qué es lo jurídico en el caso concreto, y otra vertiente ejecutiva, encaminada a «hacer ejecutar lo juzgado» o transformar la realidad para que se adecue a lo declarado previamente como conforme a Derecho. Y a los ciudadanos se les reconoce un genuino derecho fundamental a que los órganos jurisdiccionales ejerciten dicha potestad jurisdiccional, también en su vertiente ejecutiva, a través de los procedimientos que las leyes establezcan (ver art. 117.3 CE), siempre que hagan valer sus pretensiones de tutela ejecutiva de conformidad -igualmente- con lo dispuesto en las leyes procesales.

${ }^{8}$ En la misma línea, entre otras muchas, en la STC 206/1993, de 22 de junio (FJ 2), se afirma que: «este derecho fundamental no se satisface con una mera declaración judicial, desprovista de sustancia práctica, sino que necesita de su realización y, por tanto, la tutela, en cuanto efectiva por exigencia constitucional expresa, ha de llegar hasta el cumplimiento forzoso, si preciso fuere, de los pronunciamientos judiciales, donde se exterioriza la potestad de juzgar. Esto ha sido dicho tantas veces, con unas o con otras palabras por este Tribunal, que releva de una cita al por menor del copioso cuerpo de sentencias en las que se contiene tal afirmación». 
Todos los sujetos jurídicos, sean de carácter público o privado, tienen la obligación de cumplir las resoluciones judiciales firmes y deben colaborar con los tribunales en la ejecución de lo resuelto, como dispone el artículo 118 de la Constitución. Este mandato constitucional resulta de gran trascendencia para la vigencia efectiva del Estado de Derecho, tal y como ha manifestado el TC en diversas ocasiones; así en la temprana STC 67/1984, de 7 de junio (FJ 2), donde se incide en que este deber alcanza de forma especial a los poderes públicos:

«La ejecución de las Sentencias - en sí misma considerada- es una cuestión de capital importancia para la efectividad del Estado social y democrático de Derecho que proclama la Constitución -art. 1-, que se refleja -dentro del propio Título Preliminar- en la sujeción de los ciudadanos y los Poderes Públicos a la Constitución y al resto del ordenamiento jurídico, cuya efectividad - en caso de conflicto- se produce normalmente por medio de la actuación del Poder Judicial -arts. 117 y siguientes de la Constitución- que finaliza con la ejecución de sus Sentencias y resoluciones firmes. Por ello, difícilmente puede hablarse de la existencia de un Estado de Derecho cuando no se cumplen las Sentencias y resoluciones judiciales firmes, y de aquí que el art. 118 de la Constitución establezca que «es obligado cumplir las Sentencias y demás resoluciones firmes de los Jueces y Tribunales, así como prestar la colaboración requerida por éstos en el curso del proceso y en la ejecución del mismo». Cuando este deber de cumplimiento y colaboración -que constituye una obligación en cada caso concreto en que se actualiza- se incumple por los Poderes Públicos, ello constituye un grave atentado al Estado de Derecho, y por ello, el sistema jurídico ha de estar organizado de tal forma que dicho incumplimiento -si se produjera- no pueda impedir en ningún caso la efectividad de las Sentencias y resoluciones judiciales firmes».

En cualquier caso, sea un sujeto particular o sea un órgano público el que incumple una sentencia de condena, el beneficiado por la misma dispone de un auténtico derecho subjetivo, que tiene carácter de derecho fundamental, al entroncar directamente con el derecho a la tutela judicial efectiva del artículo 24.1 de la CE, y es calificable de derecho subjetivo público, pues se exige respecto de los órganos jurisdiccionales del Estado, que son a quienes se reclama que ejerciten la potestad jurisdiccional en su vertiente ejecutiva. Como continúa la sentencia recién citada: «El art. 24.1 de la Constitución, al establecer el derecho a la tutela judicial efectiva-que comprende el de ejecución de las Sentencias según hemos indicado- viene así a configurar como un derecho fundamental de carácter subjetivo, lo que, desde una perspectiva objetiva, constituye un elemento de trascendental importancia en el sistema jurídico»?

9 En plena coherencia con la sentencia citada, en la poco posterior STC 16/1986, de 31 de enero (FJ 3), se califica del mismo modo el derecho a la ejecución de que tratamos: 
Este derecho fundamental, aunque reconocido por la Constitución en tanto que derivado del artículo 24.1 de la $\mathrm{CE}$, es un derecho de configuración legal. Lo que significa que su contenido y alcance, así como las condiciones y los requisitos de su ejercicio, deben definirse por las normas legales; como así sucede en las normas procesales de cada rama jurisdiccional. En este sentido, resulta muy expresiva, entre otras muchas, la STC 107/1992, de 1 de julio (FJ 2), que declara ${ }^{10}$ :

«Junto a ello, este Tribunal igualmente ha afirmado que no tratándose de un derecho de libertad, sino de un derecho prestacional, el de tutela judicial efectiva, en sus distintas vertientes -y entre ellas la de la ejecución de Sentencias-, es conformado por las normas legales que determinan su alcance y contenido concretos y establecen los requisitos y condiciones para su ejercicio. De este modo, al tratarse de un derecho de configuración legal, el legislador puede establecer límites al pleno acceso a la ejecución de las Sentencias, siempre que los mismos sean razonables y proporcionales respecto de los fines que lícitamente puede perseguir el legislador en el marco de la Constitución (STC 4/1988). Consecuentemente, cabe que un Tribunal adopte una decisión de inejecución de una Sentencia, siempre que se haga expresamente en resolución motivada y con fundamento en una causa obstativa de la ejecución prevista por el ordenamiento. La aplicación judicial de una causa legal de inejecución debe estar guiada por el principio pro actione que inspira todas las manifestaciones del art. 24.1 $\mathrm{CE}$, de manera que debe adoptarse la interpretación más favorable a la efectividad del derecho a la tutela judicial, en este caso del derecho a la ejecución. La denegación de la ejecución no puede, pues, ser arbitraria ni irrazonable, ni fundarse en una causa inexistente, ni en una interpretación restrictiva del derecho fundamental (STC 33/1987)».

Por tanto, el legislador puede establecer $-\mathrm{y}$ de hecho establece-requisitos y condiciones para el ejercicio del derecho fundamental a la ejecución, sin que esto lesione el derecho a la tutela judicial efectiva, del mismo modo a como sujeta el derecho a una sentencia sobre el fondo tanto al cumplimiento de una serie de requisitos procesales (relativos al tribunal, a las partes y al propio procedimiento) como a la ausencia de ciertos óbices de naturaleza igualmente procesal (como la litispendencia y la cosa jugada); de forma

«Exigencia objetiva del sistema jurídico, la ejecución de las Sentencias y demás resoluciones que han adquirido firmeza también se configura como un derecho fundamental de carácter subjetivo incorporado al contenido del art. 24.1 de la C.E., cuya efectividad quedaría decididamente anulada si la satisfacción de las pretensiones reconocidas por el fallo judicial en favor de alguna de las partes se relegara a la voluntad caprichosa de la parte condenada o, más en general, éste tuviera carácter meramente dispositivo».

${ }^{10}$ Sobre esta cuestión y con cita de esta sentencia, Ruiz-Rico Ruiz y Carazo Liébana: ob. cit., pp. 351 a 352 . 
análoga, la ley condiciona el derecho a la ejecución a que el ejecutante observe ciertos presupuestos procesales y presente un título ejecutivo con los requisitos que la misma ley también exija ${ }^{11}$. Además, las leyes procesales pueden fijar limitaciones a la ejecución que sean razonables y respondan a un fin legítimo, como sucede, por ejemplo: con las previsiones sobre el carácter inembargable de determinados bienes; o con las normas que señalan plazos de caducidad para el ejercicio de la acción ejecutiva; o con aquellas que regulan los supuestos en los que cabe suspender la ejecución, entre otras ${ }^{12}$.

Ahora bien, en todos los casos en que la ley establezca un requisito o una limitación que afecten al derecho a la ejecución, según la jurisprudencia constitucional citada, en primer término se hace preciso que la previsión legal sea razonable, sirva a un fin legítimo y resulte proporcionada respecto a la restricción que supone para nuestro derecho fundamental; y en segundo lugar, es necesario que los tribunales, cuando controlen la observancia o no del precepto legal de que se trate, lo hagan conforme al ya invocado "principio pro actione», esta vez en el sentido de que realicen dicho examen de la forma más favorable al desarrollo o continuación del proceso de ejecución, sin que puedan adoptar decisiones de «inejecución» que sean claramente arbitrarias o irrazonables.

Acerca de lo primero, en alguna ocasión el TC ha declarado contraria al derecho a la tutela judicial efectiva una ley que establecía limitaciones al derecho a la ejecución, por considerarlas excesivas y desproporcionadas en relación con el fin que perseguían; así, por ejemplo, en la STC 113/1989, de 22 de junio, que declaró inconstitucional un precepto de la Ley General de la Seguridad Social por cuanto prohibía el embargo de las prestaciones de la Seguridad Social de manera incondicionada y al margen de su cuantía. Y es que, como dispone esta sentencia (en su FJ 3):

«(...) esta potestad de mediación legislativa de los derechos que se integran en el de tutela judicial no es absoluta, ni dependiente del arbitrio del legislador, pues, dentro del respeto debido al contenido esencial de los derechos fundamentales, resulta indiscutible que el art. 24.1 de la Constitución

${ }^{11}$ Así, por ejemplo, en el orden civil, la LEC requiere para que se pueda despachar ejecución: que el actor presente un título de los previstos en el artículo 517, que lo haga ante el tribunal dispuesto en los artículos 545 y 546, que se cumplan los requisitos de las partes recogidos en los artículos 538 a 544, que la demanda tenga el contenido exigido en el artículo 549 y se acompañe de los documentos indicados en el artículo 550, y que no se presente antes del plazo señalado en el artículo 548 si se refiere a un título ejecutivo judicial, etc.

${ }_{12}$ Por continuar con lo dispuesto en la LEC, véanse los artículos 605 a 607 sobre el carácter inembargable de ciertos bienes; o el artículo 518, que establece un plazo de caducidad para las acciones ejecutivas basadas en título judicial; o los preceptos relativos a la suspensión de la ejecución forzosa, artículos 565 a 569 . 
exige, según la STC 158/1987, ausencia de condicionamientos que dificulten o entorpezcan, en lo que aquí interesa, la posibilidad de que lo resuelto por los órganos judiciales sea cumplido en sus propios términos, de manera que, cuando el legislador imponga requisitos o limitaciones al ejercicio del derecho fundamental, su legitimidad constitucional habrá de ser examinada para comprobar si responden a razonables finalidades de protección de valores, bienes o intereses constitucionalmente protegidos y guardan debida proporcionalidad con dichas finalidades, lo cual significa que serán inconstitucionales, por vulneración del derecho fundamental, aquellos requisitos, formalidades y limitaciones que comprometen su ejercicio de tal forma que no resulten comprensibles a la luz de una ponderación razonable y proporcionada de los valores acogidos en la Constitución» ${ }^{13}$.

Y respecto a lo segundo, una vez establecido legalmente un requisito del que se hace depender el derecho a la ejecución, o una limitación que afecte a su ejercicio, o una situación que condicione la continuación del proceso... corresponde a los tribunales de la jurisdicción ordinaria valorar si se cumple o no lo previsto en las normas, teniendo en cuenta el «principio pro actione»; y el Tribunal Constitucional únicamente podrá revisar si la aplicación judicial que se ha hecho de la norma es manifiestamente infundada. Como ejemplo claro de esto, en la STC 210/1993, de 28 de junio (FJ 3), se declara sobre la apreciación de una causa de suspensión de la ejecución:

«No corresponde a este Tribunal revisar la corrección o incorrección de tal razonamiento judicial, pues esta cuestión, de estricta legalidad ordinaria, escapa del contenido propio de esta vía de amparo constitucional, sino tan sólo considerar si la suspensión de ejecución acordada lo ha sido razonadamente y no de forma arbitraria o carente de fundamento. Como quiera que la suspensión se encuentra motivada, aplica una causa legal (la medida cautelar acordada en el proceso declarativo ulterior) y se efectúa con expresa ponderación de los efectos y naturaleza de las decisiones que recaigan en ambos procedimientos, interdictal y declarativo, así como, finalmente, con adopción de garantías con relación a los perjuicios que de ellas puedan derivarse, no puede estimarse la misma como irrazonable o arbitraria y, por ende, vulneradora del derecho fundamental a la ejecución de lo resuelto que se invoca».

En cuanto al contenido del derecho a la ejecución forzosa como derecho fundamental, nótese que, para el TC, el derecho a la ejecución se encuentra ligado a otro derecho que también juzga incluido en el artículo 24.1 de la CE

${ }^{13}$ En otros casos, teniendo en cuenta esta misma doctrina, el balance del TC ha llegado al resultado contrario y no ha entendido como lesivas del derecho a la ejecución las limitaciones legales a las que se refería, como en la STC 73/2000, de 14 de marzo (ver especialmente los FJ 10 y 11). 
y que considera como su presupuesto lógico y constitucional: nos referimos al derecho a la intangibilidad de las resoluciones firmes. De hecho, el TC entiende que existe un derecho más amplio, dentro del derecho a la tutela judicial efectiva, que es «el derecho a que las resoluciones judiciales alcancen la efectividad otorgada por el Ordenamiento», y que tiene una doble manifestación: «de un lado, el derecho a que las resoluciones judiciales firmes se ejecuten en sus propios términos y, de otro, el respeto a su firmeza y a la intangibilidad de las situaciones jurídicas en ellas declaradas (SSTC 171/1991, de 16 de septiembre, FJ 3; 198/1994, de 4 de julio, FJ 3; 197/2000, de 24 de julio, FJ 2; 83/2001, de 26 de marzo, FJ 4, entre otras muchas)»; así se expresa en la STC 312/2006, de 8 de noviembre (FJ 4), así como en otras, como las SSTC 5/2003, de 20 de enero (FJ 5) y 209/2005, de 18 de julio (FJ 2). Analicemos a continuación qué relación y dependencia existen entre uno y otro derecho ${ }^{14}$.

\section{RELACIÓN ENTRE EL DERECHO A LA EJECUCIÓN Y EL DERECHO A LA COSA JUZGADA}

Como se acaba de adelantar, el derecho fundamental a la ejecución forzosa de las sentencias firmes tiene como base y presupuesto el derecho a la intangibilidad o invariabilidad o inmodificabilidad de las resoluciones judiciales que sean firmes. Así se declara en numerosas sentencias del TC, como en la 1/1997, de 13 de enero (FJ 3), que nos sirve de muestra:

«Corolario de lo dicho es que la actividad jurisdiccional dirigida a esa finalidad de ejecutar lo juzgado ha de respetar escrupulosamente el fallo o parte dispositiva y ejercitarse con energía e intensidad suficientes para superar los obstáculos que pudieran oponérsele (STC 153/1992). En tal sentido, el derecho a la ejecución impide que el órgano judicial encargado de ella, aunque sea el mismo que dictó la Sentencia, se aparte de lo mandado en el pronunciamiento a cumplir o se abstenga de adoptar las medidas necesarias

${ }^{14}$ García Pons, E., entiende que las dos manifestaciones señaladas, unidas a la necesidad de que la ejecución se produzca sin dilaciones indebidas, forman el contenido esencial del derecho a la ejecución que recoge el artículo 24.1 de la CE: «El Tribunal Constitucional distingue en el derecho a la ejecución de sentencia tres manifestaciones que integran el contenido fundamental del derecho a la tutela judicial efectiva, a saber: $1^{\text {a }}$ ) Derecho a la intangibilidad de las resoluciones judiciales firmes no susceptibles de ser modificadas por vías que no sean las legalmente previstas; $2^{\mathrm{a}}$ ) Derecho a que las resoluciones judiciales firmes se ejecuten en sus propios términos; y $3^{a}$ ) Derecho a que la ejecución se produzca sin dilaciones indebidas») (en Ejecución de sentencia. El derecho a la ejecución de sentencia como manifestación prestacional del contenido fundamental del derecho a la tutela judicial efectiva según la doctrina del Tribunal Constitucional, PPU, Barcelona, 1995, p. 17 y ss.). 
para conseguirlo (SSTC 306/1993 y 322/1994). Ello significa entonces que tal derecho tiene como presupuesto lógico y aun constitucional, la intangibilidad de la firmeza de las resoluciones judiciales y de las situaciones jurídicas allí declaradas (STC 135/1994), sin que, por lo mismo, puedan ser introducidas en el procedimiento de ejecución, para alterar el contenido de la parte dispositiva de la Sentencia, cuestiones no abordadas en ella ni decididas en el fallo que se trate de ejecutar o con las que éste no guarde una directa e inmediata relación de causalidad (SSTC 91/1993 y 219/1994)» ${ }^{15}$.

Es bien sabido que cuando una resolución judicial alcanza firmeza tiene como efecto que ya no puede ser modificada, de suerte que lo decidido en ella vincula tanto al propio órgano que la ha dictado y a las partes a quienes se dirige, como a otros potenciales tribunales y sujetos jurídicos. Este efecto vinculante, denominado fuerza de cosa juzgada, se califica de formal cuando se proyecta respecto del propio proceso en el que se dicta la resolución, y adquiere el calificativo de material cuando tiene repercusión hacia otros eventuales procesos que puedan abrirse. Así, cuando algo se resuelve con fuerza de cosa juzgada, ya no puede cambiarse. Es más, desde que las resoluciones son firmadas por quienes las dictan devienen invariables, lo que significa que sólo se permiten las correcciones o los añadidos no sustanciales que caben al amparo del artículo 267 de la $\mathrm{LOPJ}^{16}$. Si una resolución -invariable- no es firme, aún podrá modificarse su contenido por medio de los recursos legalmente previstos. Pero si la resolución adquirió firmeza, únicamente podrá pretenderse la entera rescisión de la sentencia firme -sólo de las sentencias- a través de los excepcionales mecanismos previstos para este fin ${ }^{17}$.

${ }^{15}$ Recogen y comentan algunas sentencias relevantes sobre la intangibilidad de las resoluciones firmes Oleo Banet, F. y Pérez Nieto, R., «El derecho a la tutela judicial efectiva y las garantías constitucionales del proceso», en La Constitución Europea, Tribunal Constitucional y Centro de Estudios Políticos y Constitucionales, Madrid, 2005, pp. 292 y ss.

${ }^{16}$ Existe un buen número de sentencias del TC en las que se perfila qué puede hacerse y qué no puede hacerse - por considerarse lesivo de la invariabilidad de las resoluciones firmes y por ello del derecho a la tutela judicial efectiva- con apoyo en los expedientes previstos en el artículo 267 LOPJ. Así, García Pons (ob. cit., pp. 38 a 41) se refiere a la STC 23/1994, de 27 de enero (FJ 1); Oleo Banet y Pérez Nieto (ob. cit., pp. 294 a 298) comentan las SSTC 31/2004, de 4 de marzo (FJ 6) y 49/2004, de 30 de marzo (FJ 2); y Garberí Llobregat (ob. cit., pp. 239 a 245) alude a las SSTC 286/2006, de 9 de octubre (FJ 2); 289/2006, de 9 de octubre (FJ 3); 357/2006, de 18 de diciembre (FJ 2); 171/2007, de 23 de julio (FJ 2). Y más recientemente, la STC 89/2011, de 6 de junio (FFJJ 4 y 5), trata de la misma cuestión.

${ }^{17}$ El TC también tiene declarado desde hace tiempo que no es contrario a la exigida intangibilidad de las resoluciones firmes que existan tales mecanismos excepcionales. Así, por ejemplo, en la STC 15/1986, de 31 de enero (FJ 3): «No quiere decir ello que la formulación constitucional impida al legislador sacrificar la «santidad de la cosa juzgada» en aras del superior valor de la justicia, estableciendo supuestos de firmeza potencialmen- 
En consecuencia, cuando se procede a la ejecución de una sentencia firme y de contenido condenatorio, el proceso de ejecución debe proyectarse exclusivamente sobre lo dispuesto en el fallo, sin que pueda aprovecharse este proceso: i) ni para modificar indebidamente lo resuelto en la sentencia, pretendiendo que la ejecución también alcance a aspectos que aquélla no recogía; ii) ni para que la ejecución se proyecte sobre sujetos a los que tampoco se refería la sentencia ni la ley permita hacer extensivos sus efectos; y iii) ni, en cualquier caso, para discutir cuestiones que ya quedaron zanjadas y resueltas con «autoridad de cosa juzgada» (ex art. 207.3 LEC).

De este modo, los tres supuestos mencionados recogen quiebras de la cosa juzgada producidas con ocasión de un proceso de ejecución y muestran cómo la intangibilidad de las resoluciones firmes es un presupuesto necesario del derecho a la ejecución forzosa; aunque este derecho tenga el carácter de fundamental, si en su ejercicio no se respeta la eficacia de cosa juzgada o la invariabilidad de las resoluciones, se lesionará el derecho a la tutela judicial efectiva, como ha declarado el TC (y veremos enseguida con algunos ejemplos). Así, si en un primer momento la intangibilidad de las resoluciones firmes se introdujo en el cuadro de derechos del artículo 24.1 de la CE precisamente por ser un presupuesto lógico del derecho a la ejecución, al estar éste incluido sin duda en el derecho a la tutela judicial efectiva ${ }^{18}$, posteriormente, la misma intangibilidad se ha convertido en un límite y contrapeso del derecho a la ejecución, y las vulneraciones de la cosa juzgada en el proceso de ejecución pueden tener alcance constitucional.

Veamos algún ejemplo -en la jurisprudencia del TC- de los tres supuestos a los que acabamos de referirnos, que nos ayuden a perfilar más la

te debilitada; lo que el derecho a la tutela judicial efectiva proscribe es que, fuera de los supuestos taxativamente previstos, las resoluciones firmes no queden sin efecto. Como indicamos en la Sentencia 67/1984, de 7 de junio, los principios de seguridad jurídica y de legalidad en materia procesal (art. 9.3 y 117.3 de la C.E.) vedan a los Jueces y Tribunales, fuera de los casos previstos por la Ley, «revisar el juicio efectuado en un caso concreto, si entendieran con posterioridad que la decisión no se ajusta a la legalidad», sea ésta sustantiva o meramente objetiva».

${ }_{18}$ Así se declara, por ejemplo, en la STC 119/1988, de 20 de junio (FJ 2): «También ha sostenido este Tribunal que presupuesto para el ejercicio de tal derecho del justiciable a instar la ejecución de lo juzgado es el principio de la intangibilidad de las Sentencias que «entra a formar parte, por lo mismo, del cuadro de garantías que el art. 24.1 de la Constitución consagra», de modo que el derecho a la tutela judicial efectiva proscribe que, fuera de los supuestos taxativamente previstos, las resoluciones firmes queden sin efecto (STC 15/1986, de 31 de enero)»; o también, entre otras muchas, la STC 86/2005, de 18 de abril (FJ 2): «De ahí que, en estos casos, el derecho a la intangibilidad de las resoluciones judiciales firmes, al constituir un presupuesto lógico del derecho a la ejecución de las resoluciones judiciales firmes, se integre en este derecho fundamental (SSTC 49/2004, de 30 de marzo, FJ 2; 116/2003, de 16 de junio, FJ 3)». 
relación entre el derecho a la ejecución y el derecho a la cosa juzgada, desde la perspectiva del derecho a la tutela judicial efectiva. Como ejemplo reciente del primer supuesto, la STC 35/2018, de 23 de abril (FJ 3), tras recordar, con carácter general, la doctrina constitucional de que estamos tratando en este punto $^{19}$, procede a estimar un recurso de amparo relativo al siguiente caso: se dictó una sentencia de modificación de medidas de un proceso de divorcio previo, que decretaba el cese de la obligación de alimentos que tenía un padre para con su hijo, declarando que este cese no tendría efectos retroactivos sino que sería eficaz desde la propia sentencia; esta sentencia no fue recurrida y adquirió firmeza, y cuando el hijo instó la ejecución de deudas por alimentos pendientes y anteriores al mencionado cese, el padre se opuso a la ejecución alegando abuso de derecho, por cuanto las cantidades reclamadas se correspondían con una época en la que el alimentista trabajaba y disponía de ingresos económicos; esta alegación fue desestimada por el juez ejecutor, pero el órgano de apelación la acogió, lo cual fue considerado lesivo del artículo 24.1 de la CE por el TC, ya que vulneraba la intangibilidad de la sentencia firme que declaró el cese de la obligación sin efectos retroactivos, en la medida en que se intentó modificar el fallo de la misma a través del proceso de ejecución.

Como ejemplo del segundo supuesto, en el caso de la STC 53/2010, de 4 de octubre (FJ 5), se despachó ejecución contra consejeros de una sociedad a los que no se había demandado en el proceso declarativo previo, por lo que se extendieron indebidamente los efectos de la cosa juzgada, contraviniendo lo dispuesto en los artículos 538.2 y 542.1 de la LEC (que sólo permiten instar la ejecución contra los deudores solidarios a los que se haya demandado y consten así en el título de condena). En estos casos no es necesario acudir

19 «Es importante destacar que, como se recuerda en la STC 89/2011, de 6 de junio, FJ 4, con cita de la STC 53/2007, de 12 de marzo, FJ 2, el principio de invariabilidad de las resoluciones judiciales firmes es una consecuencia, tanto del principio de seguridad jurídica (art. 9.3 CE), como, sobre todo, del derecho a la tutela judicial efectiva sin indefensión (art. 24.1 CE), habida cuenta de que «este derecho asegura a los que han sido parte en un proceso que las resoluciones judiciales definitivas dictadas en el mismo no sean alteradas o modificadas fuera de los cauces legales establecidos para ello» (SSTC 180/1997, de 27 de octubre, FJ 2, 48/1999, de 22 de marzo, FJ 2, y 218/1999, de 29 de noviembre, FJ 2, entre otras), pues si el órgano jurisdiccional modificara una Sentencia fuera del correspondiente recurso establecido al efecto por el legislador, quedaría asimismo vulnerado el derecho a la tutela judicial, puesto que ésta carecería de eficacia si se permitiera reabrir un proceso ya resuelto por resolución firme (SSTC 180/1997, de 27 de octubre, FJ 2, y 56/2002, de 11 de marzo, FJ 4, entre otras). Por ello, «el derecho fundamental reconocido en el art. 24.1 CE actúa como límite... incluso en la hipótesis de que con posterioridad entendieran que la decisión judicial no se ajusta a la legalidad» (SSTC 48/1999, de 22 de marzo, FJ 2; 218/1999, de 29 de noviembre, FJ 2; 96/2005, de 28 de abril, FJ 5, y 115/2005, de 9 de mayo, FJ 4)». 
a la vulneración de la intangibilidad de las resoluciones firmes para fundar la lesión del artículo 24.1 de la CE, pues es suficiente con la indefensión consistente en soportar la ejecución de una sentencia fruto de un proceso en el que no se pudo participar.

En la misma línea, en la STC 153/2006, de 22 de mayo (FJ 3), se parte del derecho a la ejecución como parte integrante del derecho a la tutela judicial efectiva, pero tal derecho lo es a la ejecución de la sentencia «en sus propios términos» (art. 18.2 LOPJ), lo que implica: «que la actividad ejecutiva no puede dirigirse contra persona ajena al fallo y, más en concreto aún en el ámbito de la jurisdicción civil, que la ejecución de la sentencia tiene como destinatarios únicos y únicos protagonistas a las partes y más específicamente al condenado en la sentencia, de modo que en ningún caso cabe derivar la acción ejecutiva hacia personas distintas sin destruir la misma esencia de la cosa juzgada (SSTC 166/2003, de 29 de septiembre, FFJJ 6 y 7 , y 229/2000, de 2 de octubre, FFJJ 2 y 3)».

Por último, sobre el tercer supuesto antes aludido, valga de ejemplo lo dispuesto en la STC 18/2004, de 23 de febrero (FJ 4), que considera lesivo del artículo 24.1 de la CE, en su vertiente del derecho a la ejecución, volver a replantear durante el proceso de ejecución cuestiones que ya se resolvieron en el proceso declarativo, o pretender dar valor en aquél a lo que se consideró irrelevante en éste. Así:

«Pues bien, desde la perspectiva del art. $24 \mathrm{CE}$, no puede aceptarse que sin el concurso de elementos que hagan imposible física o jurídicamente la ejecución o la dificulten por concurrir circunstancias sobrevenidas impeditivas, por incorrecta determinación del fallo, por sus desproporcionadas consecuencias o por razones similares (como era el caso de las SSTC 194/1991, de 17 de octubre, FJ 4; 153/1992, de 19 de octubre, FFJJ 4 y 5; 140/2003, de 14 de julio, FJ 7; y AATC 621/1985, de 25 de septiembre, FJ 2; 222/1989, de 4 de mayo, FJ 2; y 4/1992, de 13 de enero, FJ 2), esto es, que sin haberse alterado los términos en los que la disputa procesal fue planteada y resuelta ante la Sala sentenciadora, se pretenda privar de efectos, en un momento posterior, al pronunciamiento judicial entonces emitido, por la vía de discutir de nuevo, en trámite de ejecución, lo que ya fue en su día definitivamente resuelto por el órgano judicial (STC 41/1993, de 8 de febrero, FJ 2), o de dar valor en esa fase final a lo que se consideró en su momento irrelevante para incidir en el resultado del proceso declarativo y en el derecho de los actores a proseguirlo para la obtención del derecho reclamado ${ }^{20}$.

${ }^{20}$ Con la misma doctrina, García Pons (ob. cit., pp. 105 a 110) cita de ejemplo la STC 314/1994, de 28 de noviembre (FFJJ 2 y 3), que estimó el amparo solicitado por cuanto en el proceso de ejecución se enjuició de nuevo lo ya resuelto en el proceso declarativo, con 


\section{EL DERECHO A LA EJECUCIÓN DE LA SENTENCIA EN SUS PROPIOS TÉRMINOS}

El derecho a la ejecución como derecho fundamental reconocido en el artículo 24.1 de la CE se traduce principalmente, según la jurisprudencia constitucional, en el derecho a que la sentencia obtenida sobre el fondo del asunto, fundada y congruente, sea ejecutada «en sus propios términos». Esto tiene apoyo en la concreción legal que se realiza en el artículo 18.2 de la LOPJ, cuyo tenor literal recordamos ahora: «Las sentencias se ejecutarán en sus propios términos. Si la ejecución resultare imposible, el Juez o Tribunal adoptará las medidas necesarias que aseguren la mayor efectividad de la ejecutoria, y fijará en todo caso la indemnización que sea procedente en la parte en que aquélla no pueda ser objeto de cumplimiento pleno...». En consecuencia, el órgano jurisdiccional encargado de la ejecución tiene que utilizar todos los medios razonables que estén a su alcance para hacer efectivo el contenido de la sentencia de que se trate; para ello, tendrá que remover los obstáculos que la parte ejecutada presente a la hora de cumplir con la prestación a la que se le haya condenado. El tribunal de la ejecución tiene así la obligación de acordar las medidas que sean precisas para ese fin -en coherencia con el derecho fundamental de carácter prestacional del que estamos tratando- y será él quien decida qué actuaciones serán las más adecuadas, de conformidad con lo dispuesto en las leyes procesales que sean aplicables; en caso de que no se emplee la diligencia debida, se producirá una lesión del derecho a la tutela judicial efectiva de la parte ejecutante. En este sentido, nos parece muy expresiva la STC 251/1993, de 19 de julio (FJ 3), en la que se afirma:

«El derecho a la ejecución impide que el órgano judicial se aparte, sin causa justificada de lo previsto en el fallo que ha de ejecutar, o que se abstenga de adoptar las medidas necesarias para proveer a la ejecución de la misma, cuando ello sea legalmente exigible. El contenido principal del derecho consiste, pues, en que esa prestación jurisdiccional sea respetuosa con lo fallado y enérgica, si fuera preciso, frente a su eventual contradicción por terceros (SSTC 32/1982, fundamento jurídico $2^{\circ}$; 125/1987, fundamento jurídico $2^{\circ}$; $153 / 1992$, fundamento jurídico $4^{\circ}$ )». Y poco más adelante se añade (dentro del mismo FJ 3): «No es cometido de este Tribunal la determinación de cuáles sean las decisiones que, en cada caso, hayan de adoptarse para la ejecución de lo resuelto, pero sí deberá vigilar, cuando de la reparación de eventuales lesiones del derecho a la tutela judicial se trate, que ésta no sea debida a una decisión arbitraria ni irrazonable, ni tenga su origen en la pasividad o desfallecimiento de los órganos judiciales

el pretexto de que había cambiado el criterio jurisprudencial sobre la norma aplicable para resolver la controversia de fondo. 
para adoptar las medidas necesarias que aseguren la satisfacción de ese derecho (SSTC 125/1987, fundamento jurídico $2^{\circ}$; 167/1987, fundamento jurídico $3^{\circ} ; 148 / 1989$, fundamento jurídico $3^{\circ} ; 153 / 1992$, fundamento jurí$\left.\operatorname{dico} 4^{\circ}\right)$ ».

Por tanto, el derecho fundamental a la ejecución de la sentencia en sus propios términos requiere partir del fallo dictado, examinando todo su alcance, para no separarse de él. Y esto conlleva una doble exigencia, como adelantábamos, pues, desde una perspectiva negativa, el órgano ejecutor no podrá modificar el contenido de lo decidido con firmeza y estará vinculado a ello, sin que pueda abrir un nuevo debate sobre lo ya resuelto ni extender la ejecución más allá de lo resuelto, según hemos visto en el apartado anterior; y desde una perspectiva positiva, ha de esforzarse para que todo lo resuelto se lleve a término, adoptando las medidas coercitivas que sean necesarias para con el ejecutado, en el ejercicio de su potestad jurisdiccional $(\text { ex art. } 117.3 \mathrm{CE})^{21}$.

El TC insiste en que la elección de cuáles sean esas medidas corresponde al órgano de la jurisdicción ordinaria, competente para la ejecución, dentro claro está- de lo que permita el Ordenamiento; al igual que es atribución de estos órganos analizar el significado y el alcance del fallo judicial que se ha de ejecutar. En modo alguno puede el TC ocuparse de estas tareas, sino que su misión -calificada por él mismo de un «control negativo»-se reduce a examinar si la interpretación de los términos del fallo efectuada por el órgano ejecutor ha sido incongruente o manifiestamente irrazonable o basada en un error patente, o si, por otro lado, dicho órgano no ha empleado toda la diligencia que le era exigible para dotar de efectividad a lo dispuesto en el fallo.

En esta línea, en la STC 11/2008, de 21 de enero (FJ 6), se declara que: «el alcance del control a efectuar por parte de este Tribunal del cumplimiento de la potestad jurisdiccional de hacer ejecutar lo juzgado (art. 117.3 $\mathrm{CE}$ ) no es ilimitado, pues también hemos advertido que a los órganos judiciales corresponde, en el ejercicio de la función jurisdiccional que constitucionalmente les resulta conferida, la interpretación de los términos del fallo y la del alcance que quepa atribuir a la cosa juzgada, así como la decisión de si aquél ha sido ejecutado o no correctamente y la adopción de las

${ }^{21}$ Como señala Garberí Llobregat (ob. cit., pp. 168 a 169): «De esta forma el derecho a que la sentencia se ejecute en sus propios términos tiene un carácter objetivo en cuanto se refiere precisamente al cumplimiento del fallo sin alteración y no permite por tanto suprimir, modificar o agregar a su contenido excepciones o cargas que no puedan reputarse comprendidas en él. La ejecución, por tanto, ha de consistir precisamente en lo establecido y previsto en el fallo y constituye, junto al derecho del favorecido a exigir su cumplimiento total e inalterado, el del condenado a que no se desvirtúe, se amplíe o se sustituya por otro (STC 219/1994, de 28 de octubre)». 
medidas oportunas para asegurar (cuando así resulte procedente) su ejecución, apreciaciones todas ellas que únicamente resultan revisables en sede constitucional cuando han incurrido en incongruencia, arbitrariedad, carecen de razonabilidad o evidencian la dejación por parte del órgano judicial de su obligación de hacer ejecutar lo juzgado... Nuestro control es sólo de tipo negativo, y se ciñe al examen de la razonabilidad de la interpretación que los titulares de la potestad de ejecución realicen del fallo en el marco de la legalidad ordinaria. Lo que nos corresponde es garantizar que, en aras precisamente de la efectividad del derecho a la tutela judicial efectiva, los Jueces y Tribunales no lleven a cabo interpretaciones de los fallos que, por alterarlos o apartarse de ellos, incurran en arbitrariedad, incongruencia, irrazonabilidad o error (SSTC 116/2003, de 16 de junio, FJ 3;140/2003, de 14 de julio, FJ 6; 223/2004, de 29 de noviembre, FJ 6; STC 96/2005, de 18 de abril, FJ 5, entre otras)».

No obstante, hay ocasiones en las que lo dispuesto en la sentencia no puede llevarse a efecto, por mucho empeño que ponga el órgano jurisdiccional: bien porque la parte ejecutada se resiste completamente a cumplir los términos concretos que se recogen en el fallo -lo que puede ocurrir en los casos de condena no dineraria, por ejemplo, cuando se condena a un hacer personalísimo-, o bien porque el cumplimiento de la prestación específica a la que se condena resulte ya imposible. Es decir, existen supuestos en los que la ejecución in natura o in specie de la obligación ordenada en el fallo no puede obtenerse y hay que dar paso a una ejecución genérica o sustitutiva de la anterior. De suerte que el derecho a la ejecución de la sentencia «en sus propios términos» (art. 18.2 LOPJ) no cabe entenderlo en un sentido literal, sino que procede una interpretación finalista o teleológica ${ }^{22}$.

${ }^{22}$ Así lo propone, siguiendo al TC, Bermúdez Requena, J. M., «Tutela judicial efectiva y ejecución por sustitución en procesos civiles», Diario La Ley, no 6967, de 13 de junio de 2008, pp. 3 a 4): «El criterio interpretativo literal debe ceder en esta cuestión ante una interpretación teleológica o finalista sobre la efectiva aplicación práctica del derecho a la ejecución en sus propios términos, por lo que no cabría, siguiendo consolidada doctrina jurisprudencial constitucional, interpretar aquél «restrictivamente, sino más bien a favor de una ejecución satisfactoria, con lo que se quiere decir, en suma que el Juez de la ejecución ha de apurar siempre, en virtud del principio pro actione, del de economía procesal y, en definitiva, de su deber primario de tutela, la posibilidad de realización completa del fallo, infiriendo de él todas sus naturales consecuencias en relación con la causa petendi, es decir, de los hechos debatidos y de los argumentos jurídicos de las partes, que, aunque no pasan literalmente al fallo, como es lógico, sí constituyen base para su admisión o rechazo por el juzgador... Lo cual, es obvio, no supone que se puedan ampliar en fase de ejecución de Sentencias los términos del debate o hacerse otras pretensiones distintas, ampliando indebidamente el contenido de la ejecución... Simplemente implica que la interpretación y aplicación del fallo de la Sentencia no ha de ser estrictamente literal, sino finalista (art. 3 CC) y en armonía con el todo que constituye la Sentencia» [esta cita es de la STC 148/1989, de 21 de septiembre]». 
Lo anterior significa que el derecho fundamental a la ejecución forzosa no es un derecho absoluto, ya que pueden concurrir «razones atendibles» -en expresión de la jurisprudencia constitucional- que justifiquen que se acuda a una ejecución "por sustitución», a la que también alude el citado artículo 18.2 de la LOPJ: si la ejecución de la sentencia «resultare imposible», el tribunal encargado de la ejecución «fijará en todo caso la indemnización que sea procedente en la parte en que aquélla no pueda ser objeto de cumplimiento pleno»; de manera que procederá el denominado equivalente pecuniario de la prestación (no dineraria) que se haya incumplido, o bien la indemnización económica por los daños y perjuicios que dicho incumplimiento haya causado al ejecutante, y la ejecución que inicialmente era de una condena no dineraria se transformará en una ejecución dineraria. Lo anterior se hará de conformidad con las leyes procesales que sean aplicables.

Como es sabido, la LEC regula con detalle la ejecución no dineraria en los artículos 699 a 720, que resultan aplicables no sólo en los procesos civiles sino también de forma subsidiaria en otros órdenes jurisdiccionales. En esos preceptos se señalan diferentes medios que puede emplear el tribunal para lograr en lo posible la ejecución in natura de lo dispuesto en el fallo, entre los que se encuentran: el señalamiento de plazos para que el condenado lleve a cabo la prestación, o el apercibimiento de apremios personales, o la imposición de multas coercitivas (art. 699), más algunos medios específicos de ciertas condenas. Además, también se distingue según cuál sea el tipo de prestación incumplida para señalar la clase de ejecución sustitutoria que corresponde. Pues en unos casos procede únicamente la sustitución «por una justa compensación económica», como ocurre cuando se ha incumplido una condena de dar cosa mueble determinada (art. 701); en otros, como en el incumplimiento de dar cosa genérica, el ejecutante podrá elegir entre la adquisición del bien a costa del ejecutado, o su equivalente económico más una indemnización de daños y perjuicios (art. 702); en cambio, para la condena de entregar un bien inmueble, no se prevé ejecución sustitutiva sino que sólo se regula cómo efectuar el lanzamiento (arts. 703 y 704); en las condenas de hacer se diferencia entre el hacer no personalísimo, cuyo incumplimiento también permite que el ejecutante opte entre que se encargue a un tercero a costa del ejecutado o que se le indemnice por no hacerlo (art. 706), y el hacer personalísimo, en el que, tras diversas medidas reforzadas de compeler al obligado, se acabará en el equivalente pecuniario de la prestación o en la adopción de «cualesquiera otras medidas que resulten idóneas para la satisfacción del ejecutante», dice la ley para estos casos (art. 709); por último, en las condenas de no hacer, la sustitución no puede ser otra que el resarcimiento de los daños y perjuicios producidos (art. 710). En consecuencia, existen muy diversas formas de proceder a la ejecución por sustitución, dependiendo de la clase de obligación incumplida. No es momento de 
estudiar la regulación legal de estas formas sustitutorias de ejecución ${ }^{23}$; nuestro punto de mira es el derecho a la tutela judicial efectiva y en qué medida tales formas son respetuosas con el derecho fundamental a la ejecución, del que estamos tratando.

Así, el citado artículo 18.2 de la LOPJ condiciona el paso de la ejecución in specie a la ejecución in genere a que la primera devenga imposible. Esta imposibilidad puede ser tanto material o natural como jurídica o legal ${ }^{24}$; y en todo caso, debe quedar acreditada y ser apreciada por el órgano jurisdiccional encargado de la ejecución, de forma motivada. Cuando esto ocurre, se respeta el derecho del artículo 24.1 de la CE, como declara el TC, por ejemplo en su sentencia 153/1992, de 19 de octubre (FJ 4):

«Cabe añadir que ese derecho a la ejecución de la Sentencia en sus propios términos no impide que en determinados supuestos ésta devenga legal o materialmente imposible, lo cual habrá de apreciarse por el órgano judicial en resolución motivada, pues el cumplimiento o ejecución de las Sentencias depende de las características de cada proceso y del contenido del fallo. Ahora bien, esa imposibilidad de dar cumplimiento a la Sentencia en sus propios términos no implica, al menos en las Sentencias condenatorias, la ausencia de toda otra medida ejecutiva, de modo que baste la mera constatación de la imposibilidad de acordar el cumplimiento estricto de los mandatos que ella contiene para entender satisfecha la tutela judicial efectiva, siendo preciso que, en tales supuestos, se acuda a la adopción de otros medios de ejecución sustitutorios o subsidiarios que el ordenamiento ofrece, pues, en caso contrario, las decisiones judiciales quedarían convertidas en meras declaraciones de intenciones, y la parte que ha obtenido una Sentencia favorable se encontraría en idéntica posición que antes de obtener dicho pronunciamiento».

En definitiva, el examen de que concurren motivos para entender que la ejecución en los términos precisos de la sentencia no puede llevarse a efecto corresponde al juez ejecutor, es él quien tiene que realizar la ponderación que se exige; pero como afirma el TC en su sentencia 58/1983, de 28 de junio (FJ 2), citada después por muchas otras: «hay que concluir que tan constitucional es una ejecución en la que se cumple el principio de la identidad total entre lo ejecutado y lo estatuido en el fallo como una ejecución en la que, por razones atendibles, la condena es sustituida por su equivalente pecuniario o por otro tipo de prestación».

${ }^{23}$ Para un estudio exhaustivo de las mismas, véase, por todos, Ortells Ramos, M., La ejecución de condenas no dinerarias en la Ley de Enjuiciamiento Civil, La Ley, Madrid, 2005. Y desde la perspectiva de su entronque con el derecho a la tutela judicial efectiva, véase el entero trabajo citado en la nota anterior, de Bermúdez Requena.

${ }^{24}$ Sobre estos dos tipos de imposibilidad, ver Bermúdez Requena: ob. cit., pp. 4 a 6 . 


\section{BIBLIOGRAFÍA}

BERMúdez RequenA, J. M., «Tutela judicial efectiva y ejecución por sustitución en procesos civiles», Diario La Ley, $\mathrm{n}^{\circ}$ 6967, de 13 de junio de 2008.

Cordón Moreno, F., «El derecho a obtener la tutela judicial efectiva», en Derechos procesales fundamentales (coord. GutiÉrrez Alviz, F.), Consejo General del Poder Judicial, Madrid, 2005.

De la Oliva Santos, A. (con Díez-Picazo Giménez Y Vegas Torres, J.), en Curso de Derecho Procesal Civil I. Parte General, Editorial Universitaria Ramón Areces, Madrid, $3^{\mathrm{a}}$ ed., 2016.

GARBERí LloBrREgAt, J., El derecho a la tutela judicial efectiva en la jurisprudencia del Tribunal Constitucional, Bosch, Barcelona, 2008.

GARcía Pons, E., Ejecución de sentencia. El derecho a la ejecución de sentencia como manifestación prestacional del contenido fundamental del derecho a la tutela judicial efectiva según la doctrina del Tribunal Constitucional, PPU, Barcelona, 1995.

Oleo BAnet, F. y Pérez Nieto, R., «El derecho a la tutela judicial efectiva y las garantías constitucionales del proceso», en La Constitución Europea, Tribunal Constitucional y Centro de Estudios Políticos y Constitucionales, Madrid, 2005.

Ortells Ramos, M., La ejecución de condenas no dinerarias en la Ley de Enjuiciamiento Civil, La Ley, Madrid, 2005.

Ruiz-Rico Ruiz y CARAzo LiÉBAnA, M. J., El derecho a la tutela judicial efectiva. Análisis jurisprudencial, Tirant lo Blanch, Valencia, 2013.

Salah Palacios, E., La tutela judicial efectiva en la jurisprudencia del Tribunal Constitucional 1981-2014, Cultiva Libros, Madrid, 2015.

VAllespín PÉrez, D., Nuevos retos del derecho a la tutela judicial efectiva en el proceso civil, CIMS, Sabadell, 2009. 


\title{
EL DERECHO A LA TUTELA JUDICIAL EFECTIVA Y EL DERECHO A LA EJECUCIÓN EN LA JURISPRUDENCIA CONSTITUCIONAL
}

\section{The right to effective judicial protection and the right to execution in constitutional jurisprudence}

\author{
Ignacio José Cubillo López \\ Universidad de Córdoba (España) \\ dc1cubli@uco.es
}

http://dx.doi.org/10.18543/ed-66(2)-2018pp347-372

\section{Copyright}

Estudios de Deusto es una revista de acceso abierto, lo que significa que es de libre acceso en su integridad. Se permite su lectura, la búsqueda, descarga, distribución y reutilización legal en cualquier tipo de soporte sólo para fines no comerciales, sin la previa autorización del editor o el autor, siempre que la obra original sea debidamente citada y cualquier cambio en el original esté claramente indicado 